\title{
ENTRE CRISE E CRÍTICA: OS COLETIVOS COMO NOVOS SUJEITOS POLÍTICOS E A RECONSTRUÇÃO DA DEMOCRACIA
}

\author{
BETWEEN CRISIS AND CRITICISM: COLLECTIVES AS NEW POLITICAL \\ SUBJECTS AND THE RECONSTRUCTION OF DEMOCRACY
}

\author{
Fernando Hoffmam ${ }^{1}$
}

\section{RESUMO}

O presente artigo tem como escopo compreender os coletivos enquanto novos movimentos sociais sob o prisma da "multidão" na perspectiva de um projeto democrático constituinte e radical. Para tanto, se objetiva compreender a "multidão" como um novo sujeito político, e nessa trilha identificar os coletivos enquanto novos movimentos sociais, para então responder ao questionamento sobre os coletivos poderem ser compreendidos enquanto sujeitos político-sociais multitudinários, tendo como espaço-tempo de ação uma democracia radical e constituinte. Para responder a esse questionamento utiliza-se como referencial metodológico, teórico-analítico o materialismo histórico no viés de Antonio Negri, em que o método considera o antagonismo entre uma subjetividade criativa e uma subjetividade constituída pelo capital. É neste sentido que se estabelecem as novas categorias de análise que permitem dar conta de novos sujeitos sociais (a multidão/o comum) e compreender os coletivos a partir dessas categorias em antagonismo às subjetividades "imperiais".

Palavras-chave: Coletivos, Democracia radical, Produção de subjetividades, Poder constituinte, Resistência.

\section{ABSTRACT}

This article aims to understand the collectives as new social movements from the "crowd" view in the perspective of a constitutive and radical democratic project. Therefore, the objective is to understand the "crowd" as a new political subject, and in this way to identify collectives as new social movements, to then answer the question about the collectives being understood as multitudinous political-social subjects, with the space-time of action a radical and constituent democracy. To answer this question, the historical materialism used by Antonio Negri is used as metodological, theoretical-analytical framework, in which the method considers the antagonism between a creative subjectivity and a subjectivity constructed by the capital. It is in this way that the new categories of analysis are established that allow to handle with new social subjects (the crowd/ the common) and to understand the collectives from these categories in opposition to the "imperial" subjectivities..

Keywords: Collective, Radical democracy, Production of subjectivities, Constituent power, Resistanse.

\footnotetext{
${ }^{2}$ Doutor e Mestre em Direito Público pela Universidade do Vale do Rio dos Sinos (UNISINOS); Bolsista PROEX/CAPES no Mestrado e Doutorado; Membro do Grupo de Pesquisa Estado e Constituição e da Rede Interinstitucional de Pesquisa Estado e Constituição, registrado junto à FDV/ES, à ESDHC/MG e ao CNPQ; Professor Adjunto I do Departamento de Direito da Universidade Federal de Santa Maria (UFSM); Líder do Grupo de Pesquisa Núcleo de Estudos do Comum (NEC) registrado junto à UFSM/RS e ao CNPQ; Especialista em Direito: Temas Emergentes em Novas Tecnologias da Informação e Bacharel em Direito pelo Centro Universitário Franciscano (UNIFRA). E-mail: ferdhoffa@yahoo.com.br
} 


\section{INTRODUÇÃO}

O presente artigo está assentado na construção teórica proposta por Antonio Negri e Michal Hardt, constituindo-se em uma leitura de tal teoria a partir de uma dada perspectiva e de uma dada problemática que se apresenta por demais atual e pertinente. Seja na obra conjunta, como na obra de Antonio Negri, os autores articulam três conceitos, sendo estes o "Império", a "multidão", e o “comum", dando um novo sentido à teoria política, social e jurídica contemporâneas.

Nesse passo, em um primeiro momento nos ocupamos em compreender o que é a "multidão" (do "comum"), e como a multitudo se articula, e se constitui como um novo sujeito político que rompe com a tradição político-democrática do estatalismo liberal, bem como desarticula o conceito de povo enquanto o único possível, desde a unidade e a homogeneização que tal provoca. Dentro dessa possibilidade se constituem os coletivos como novos movimentos sociais, apresentando-se como sujeitos político-sociais e como novas formas de organização das subjetividades em processos de luta e resistência contra o Estado e o "Império" (Parte 1).

Nessa perspectiva, num segundo momento, e como fechamento propõe-se a necessidade de reconstrução da democracia enquanto um projeto democrático constituinte e radical, como ambiente para a atuação dos coletivos compreendidos como movimentos multitudinários. Nesse contexto, os coletivos surgem como sujeitos constituintes desse processo de ruptura e reconstrução e, ao mesmo tempo, como exemplo para a construção de novas instituições democráticas multitudinárias (Parte 2).

Assim, questiona-se se os coletivos inseridos na lógica dos novos movimentos sociais podem ser considerados sujeitos político-sociais multitudinários, bem como se constituem-se como agentes potencializadores da construção de um projeto democrático radical e constituinte como ambiente para essas novas subjetividades multitudinárias. Para responder a esse questionamento, utiliza-se como referencial metodológico e teórico-analítico o materialismo histórico no viés de Antonio Negri. Aqui, certamente, cabem algumas explicações: a construção teórica de Antonio Negri se desenvolve no terreno do marxismo. No entanto, a corrente do pensamento marxista representada por Negri busca uma atualização do marxismo no sentido de situá-lo frente às dinâmicas contemporâneas, mas sem se afastar dos conceitos fundamentais do materialismo histórico marxista, que são: a) a tendência histórica, b) a abstração real, c) o antagonismo e d) a constituição da subjetividade. Conforme Antônio Negri e Michael Hardt declaram, para seguir a trilha do método de Marx, hoje, deve-se ir para além, ou afastar-se das teorias de Marx. Neste sentido, o método de Negri considera o antagonismo entre uma subjetividade criativa e uma subjetividade constituída pelo capital. É neste sentido que se estabelecem as novas categorias de análise que permitem dar conta de novos sujeitos sociais (a multidão/o comum), compreendendo os coletivos sob a ótica dessas categorias em antagonismo às subjetividades “imperiais", e como condição de possibilidade para a construção de uma democracia radical e constituinte que seja o ambiente para a "multidão do comum". 

MULTIDÃO

Desde já, é importante localizar os coletivos dentro do quadro de modificações sociais, políticas e econômicas pelo qual passamos na atualidade, pois os coletivos se colocam como sujeitos nessas e dessas mudanças, constituindo uma nova esfera de atuação dos sujeitos políticos, articulados em torno de questões primordialmente identitárias e de lutas por direitos, bem como de resistência e luta contra os aparatos de repressão e expropriação estatais e "imperiais". Dessa forma, os coletivos tem lugar importante e, pode-se dizer, central, em uma reorientação do quadro dos movimentos sociais; reorientação essa que passa por uma revisão das suas formas de constituição, organização, estruturas, práticas e dos próprios sujeitos que os compõe.

Nessa perspectiva, é importante salientar, e até mesmo deixar claro, que se falar dos coletivos nesse trabalho, ou tratar da temática dos coletivos nesse trabalho, implica necessariamente pensar novas formas de constituição do sujeito na atualidade e, com isso, apresentar novas subjetividades que não se colocam na arena política e social dentro das estruturas, formas e práticas engendradas seja pelo Direito, pelo Estado, ou pela sociedade até aqui. Os coletivos não se enquadram nas formas de participação político-social construídas e apresentadas desde a modernidade, bem como não há uma condição de necessariedade entre a atuação dos coletivos e o pertencimento ou ligação com as estruturas jurídico-estatais de participação.

Isso posto, não se quer dizer já em uma primeira advertência que os coletivos não se comunicam, organizam, dialogam, ou se utilizam das institucionalidades, mas sim, que não há uma relação intrínseca entre esses novos sujeitos e as institucionalidades postas. Veja-se que, embora, no mais das vezes haja essa ligação, isso não implica em uma limitação do modo de atuação desses sujeitos, nem em que tais sujeitos se coloquem a serviço das estruturas de poder construídas no seio da máquina estatal. Desse modo, é necessário que se parta do princípio de que os coletivos enquanto novos sujeitos político-jurídico-sociais necessitam de um outro estatuto do sujeito para se colocarem devidamente como uma nova forma de organização política e social, que evidentemente gera abalos no mundo jurídico. Sob esse prisma, é importante inserir os coletivos na perspectiva dos movimentos e sujeitos multitudinários, e, para isso, é necessário constituir antes de tudo a "multidão (do comum)"² como um novo sujeito político antagonista, de luta, e resistência diante das práticas expropriatórias, dominantes e hegemônicas concebidas pelo "Império"3.

\footnotetext{
${ }^{3}$ É importante referir, que os termos “multidão do comum”, “multidão", e multitudo, serão utilizados no presente artigo no mesmo sentido, ou seja, embora, significantes diferentes terão o mesmo significado para o presente trabalho.

${ }^{4}$ Embora, e é de extrema importância deixar claro isso, não é a intenção do presente artigo trabalhar, compreender, apresentar, os coletivos sob a ótica do "Império", invariavelmente pode-se no trabalho fazer referência a tal conceito, e, por esse motivo se faz necessário uma nota explicativa sobre o mesmo. Dito isso, o "Império" é um conceito, e não uma metáfora relacionada aos tempos imperiais, ou seja, à experiência romana, chinesa, americana - aqui se fala em continente americano - anteriores. Partindo daí, o "Império" se caracteriza pela ausência de fronteiras e, assim, estende o seu
} 
Com o apoio em Hardt e Negri, a "multidão do comum" se conforma na contemporaneidade a partir de uma redefinição do mundo do trabalho e do próprio conceito de trabalho que passa a ser visto como trabalho vivo, imaterial, cognitivo, o que faz com que o próprio capital se torne uma instância da vida das pessoas e com que o regime capitalista compreenda a produção não mais apenas como produção de mais-valia, mas também como produção social, biopolítica. Nesse sentido, a "multidão" é a "multidão do comum" que realiza o trabalho imaterial", e, dessa forma, se constitui biopoliticamente e produz uma biopolítica da vida que contrapõe a biopolítica de morte do "Império". (HARDT; NEGRI, 2016)4.

Na multidão, as singularidades não perdem nem sua forma nem sua força e potência, pois essas singularidades se relacionam afetivamente e não necessariamente por um acordo político-jurídico que as funda como uma unidade. As relações singulares são mantidas na multitudo, porém, na sua multiplicidade, gerando um movimento que se desloca do singular ao plural, e, ao mesmo tempo, do plural ao singular, sem neutralizar a pluralidade que a constitui, mas também, sem apagar as singularidades em sua forma bruta. Assentado em Hoffmam (2019), é possível compreender a "multidão" como um emaranhado de singularidades que se forma a partir e com a potência singular de cada sujeito, constituindo-os na sua multiplicidade como um sujeito afetivo e um movimento das potências singulares que se organizam multitudinariamente. Nesse ponto, é possível imaginar a organização de novos sujeitos, ou outras formas de organização dos sujeitos enquanto potências afetivas de luta e resistência, o que demarca novas formas, estruturas e práticas de se agir e participar política e socialmente que não apenas as demarcadas pelas instituições estatais - e/ou "imperiais".

poder e a sua normatividade sobre todo o mundo civilizado, abrangendo a totalidade do espaço; num segundo momento, é importante demarcar que o "Império" não nasce de processos de conquista, mas sim como uma ordem de coisas que se coloca naturalmente, e perenemente suspendendo a história e fundando uma temporalidade própria. Também é importante deixar claro que o "Império" projeta o seu poder por toda a ordem social, e não apenas pela ordem política e jurídica como espaços típicos do exercício da soberania, por isso se coloca como uma forma de biopoder, e biopoliticamente controla a própria vida dos indivíduos, até mesmo formando novas subjetividades. E, paradoxalmente, embora se estruture e movimente a partir de um estado de guerra global, o conceito de "Império" é sempre dedicado a paz; no entanto, uma paz do sistema - uma paz "imperial". Dessa forma, o conceito de "Império" é um conceito global que emana o seu poder de um único centro, mostrando-se como um poder unitário responsável por manter a paz social e produzir os seus valores éticos. (HARDT; NEGRI, 2002). "O novo paradigma é, ao mesmo tempo, estrutura e hierarquia, construção centralizada de normas e produção de legitimidade de grande alcance, espalhada sobre o espaço mundial. É configurado ab initio como dinâmica e flexível estrutura sistêmica, articulada horizontalmente [...]. [...] Alguns chamam de "governança sem governo" para indicar a lógica estrutural, às vezes imperceptível mas sempre e cada vez mais efetiva, que move todos os atores dentro da ordem global". (HARDT; NEGRI, 2002, p. 31).

${ }^{5}$ Para além de dizer o que a "multidão" é, torna-se tão importante quanto, deixar claro o que ela não é. "A multidão não pode ser compreendida nos termos da contratualidade - e em geral nos termos da filosofia transcendental. No sentido mais geral, a multidão desafia a representação porque é uma multiplicidade, indefinida e não-mensurável. O povo é representado como uma unidade, mas a multidão não é representável, porque é monstruosa em relação aos racionalismos teleológicos e transcendentais da modernidade. Em contraste com o conceito de povo, o de multidão é a carne da vida. Se por um lado contrastamos a multidão com o povo, por outro podemos contrastar a multidão com as massas, o aglomerado de gente. Muitas vezes se considera massa, aglomerado de gente, uma força social irracional e passiva, perigosa e violenta, justamente porque tão facilmente manipulada. A multidão, pelo contrário, é um agente social ativo - uma multiplicidade que age. A multidão não é uma unidade como o povo, mas podemos ver que, diferentemente das massas e do aglomerado de gente ela é organizada". (NEGRI, 2003, p. 125-126). 
Nesse contexto, os coletivos se inserem como uma nova forma de organização e, ao mesmo tempo, de abordagem dessas questões no âmbito dos movimentos sociais, bem como se mostram como um novo sujeito político que, a partir de uma multiplicidade e pluralidade de sujeitos, constitui um ser-agir diverso dos movimentos sociais anteriores; não que isso signifique renegar completamente o caminho percorrido até aqui. Os coletivos, como forma de engajamento político e social na luta por direitos, traz a marca da luta das minorias por empoderamento face às estruturas estatais e "imperiais" de controle, expropriação, e até mesmo aniquilação em alguns sentidos. Estão muito presentes nessas novas formas de organização e nesses novos sujeitos coletivos de luta comum, a luta pelos direitos das mulheres, dos negros, dos quilombolas, da comunidade LGTQ, ou seja, fortemente presentes as questões relativas à gênero e raça (PEREZ; SILVA FILHO, 2017).

Ainda, mesmo que as questões ligadas aos direitos das minorias centradas em problemáticas relativas à questão de gênero, sexualidade, raça, cor, credo, etnia, se destaquem como demandas extremamente presentes na articulação dos coletivos, não se esgota nesses temas os direitos e demandas engendrados pelos coletivos. Pode-se identificar coletivos no que tange ao direito à cidade e ao processo de urbanização nos grandes centros (sobretudo); também coletivos ligados à educação, como educação popular, também podendo-se identificar a presença de coletivos em torno de questões relativas à produção cultural, artística, seja sob a forma da música, literatura, artes plásticas, etc. ${ }^{5}$

Esses novos movimentos podem ser identificados como movimentos culturais, haja visto, a intenção por meio de ações coletivas é a de modificar a sociedade e alterar as condições de percepção sobre e inserção de diversos grupos sociais em um plano real e cotidiano de igualdade entre os sujeitos. Os movimentos sociais como os coletivos tem na luta coletiva plural, e ao mesmo tempo singular, um modelo de combate aos mecanismos institucionais de apreensão dessas lutas e desses sujeitos, pois o laço que se forma a partir desses novos sujeitos não decorre da institucionalização, mas sim da solidariedade (MAIA, 2013). O vínculo que faz surgir os coletivos enquanto sujeitos políticos multitudinários, e os faz uma nova forma de organização dos sujeitos políticos, é o vínculo da "luta-em-comum" que lhes dá um "nome-em-comum", e que os constitui pluralmente na singularidade de cada sujeito, e singularmente na pluralidade do coletivo enquanto sujeito e forma de organização política.

"Os coletivos não possuem formas institucionalizadas tais quais as de um sindicato, de um partido político ou mesmo de alguns movimentos sociais tradicionais, que com o desenvolvimento do processo histórico foram incorporando cada vez mais dispositivos formais à sua estrutura". (PEREZ; SILVA FILHO, 2017, p. 268), “o caráter rizomático e nômade dos coletivos somado à sua forma de organização independente possibilita conexões inusitadas pela co-criação, pela justaposição e pela colisão, que redesenham outras dimensões possíveis da existência, ressaltando a preocupação com a alteridade e com outros mundos, coexistentes”. (MAZIVIERO; ALMEIDA, 2017, p. 8). Essa forma

${ }^{6}$ Para maiores informações e possíveis aprofundamentos, sem a intenção de esgotar a produção nesse sentido, cabe apontar algumas publicações: (PEREIRA; GHEIRART, 2018); (MAZIVIERO; ALMEIDA, 2017); (MAGALHÃES DE LIMA, 2015); (GONÇALVES, 2010), entre outros. 
de organização coletiva, nômade, rizomática, descentralizada, plural e singular ao mesmo tempo, (a) temporal, que se faz ao mesmo tempo na precariedade e na duração, mostra claramente o sujeito multitudinário que toma forma, e desgasta as formas tradicionais de organização política e social, bem como, as formas tradicionais dos próprios movimentos sociais.

Os coletivos se mantém em uma efemeridade duradoura, movimentando-se estrategicamente por meio de práticas e ações pontuais de luta e resistência, mas ao mesmo tempo fazendo essa luta e resistência perdurarem no real, na cotidianeidade comum que une os sujeitos em uma luta que é comum nas pautas, nas práticas e nos "adversários". Essa forma coletiva rompe com a necessariedade moderna de se escolher o caminho institucional como o único possível para resistir aos poderes instituídos (MAZIVIERO; ALMEIDA, 2017). Veja-se que essa questão é naturalmente reveladora, pois, naturalmente o caminho institucional para a luta e resistência acabará limitando os movimentos dos sujeitos políticos na luta por direitos e na conquista de suas pautas, pois, lutar institucionalmente contra a própria institucionalidade é no mínimo paradoxal.

É justamente essa forma multitudinária de organização, de movimentos e práticas, que possibilita aos coletivos agregar uma série de demandas, de atividades, de propostas, de movimentações, e de frentes de luta face aos poderes instituídos. As lutas por direitos nos coletivos nunca são estanques, nunca são limitadas à determinadas pautas, e nem por determinadas ações, mas sim, tem um caráter múltiplo tanto nas postulações quanto nas ações do coletivo nas lutas por tais direitos e pelo seu lugar enquanto sujeitos (MAIA, 2013). Como mostram Maziviero e Almeida (2017), os chamados coletivos urbanos tem pautas múltiplas, como o direito à cidade, a questão urbana, desenvolvimento sustentável, formas de manifestação artística, e em comum, para além da multiplicidade e diversidade de demandas entre si, tem práticas de luta na busca pela realização dessas demandas como a organização de cursos, eventos culturais, as formas de intervenção artística ou não na cidade, formas de intervenção no espaço público, como espaço comum, entre outras várias possibilidades que se interligam independentemente da luta travada.

Sob esse ponto de vista recuperando as manifestações de junho de 2013, as quais estão bastante ligadas às práticas coletivas e às práticas e lutas dos coletivos enquanto sujeitos políticos e sociais, para determinar a sua gênese enquanto movimento multitudinário, em que as jornadas de junho expressariam um "momento multidão" de tudo que antecedeu a esse processo e se seguiu a ele. Como infere a autora, o "ser multidão" desse movimento não pode significar unidade, pois, embora corroborem na direção do manifesto e do protesto, não se colocam como unidade política necessariamente (SCHERER-WARREN, 2014). Porquanto as manifestações do já longínquo junho de 2013 girassem ao redor de determinadas pautas e demandas, havia uma pluralidade de singularidades, de grupos e coletivos entorno da luta pela concretização dessas demandas. Esses sujeitos multitudinariamente se organizavam e movimentavam sem um ponto de partida comum, pois, multitudinários que são, mas com um ponto de chegada em comum, que era a luta contra os poderes instituídos, contra a repressão, contra a expropriação a qual estavam sujeitos, e que lhes dava o "nome-comum". 
É “o encontro de 'múltiplas identidades', que apesar das diferenças na política, cooperam tendo em vista o 'benefício de uma relação em comum”" (SCHERER-WARREN, 2014, p. 18), e é nesse sentido, em que na verdade não se trata de múltiplas identidades, mas sim de singularidades múltiplas e de múltiplas singularidades, que em meio a um processo antagônico constante de resistência e luta se movem contra um sentido único no caminho de um sentido "em-comum". "O signo do comum e do qualquer é, então, o da multidão, não o de uma nova unidade racial, cultural ou qualquer outra" (MATOS, 2014, p. 241), e por isso, ainda de acordo com o autor, é que as lutas da "multidão", por serem lutas das singularidades, escapam ao esquema chantagista das estruturas e instituições estatais (e "imperiais", por minha conta) de só perceber a possibilidade dos direitos inscrita nas lutas identitárias construídas pelo próprio Estado para aprisionar as identidades em uma possibilidade única. Se não fo(r)sse assim, permanece(ria) o quadro esquemático da estatalidade no qual as identidades são fixadas e as lutas por direitos se esgotam na negatividade da construção das identidades na sua diferença e não na sua multiplicidade singular (MATOS, 2014).

Nesse caminho, podemos apontar uma série de movimentos sociais que se enquadram na lógica e sistemática dos coletivos utilizando-se de variadas formas de manifestação e práticas insurrecionais contra os poderes instituídos seja pelo Estado, seja pelo "Império". Nesse quadro de movimentos, a partir de Scherer-Warren (2014), podem ser citados os Rolezinhos, o Levante Popular da Juventude, o Movimento dos Trabalhadores Sem Teto (MTST), que inclusive se articula com coletivos na cidade de São Paulo como os coletivos Periferia Ativa e Resistência Urbana, a Marcha das Vadias, que pode ser encarada como uma forma híbrida de movimento e manifestação, entre outros.

Nesse ponto, fica claro que os coletivos, como os já citados inclusive anteriormente no presente artigo, se inserem no campo dos movimentos sociais, seja de forma clara denominando-se de coletivos e agindo como tal, seja adotando outras nomenclaturas, estruturas e formas, mas, tendo em comum práticas de luta e resistência do e pelo comum. Se os movimentos sociais assumem uma variada gama de possibilidades entre o institucionalizar-se ou não; entre as múltiplas práticas de luta e resistência, escolhendo diversas e diferenciadas formas de manifestação, de posicionamento; entre pautas, demandas e direitos que no mais das vezes são comuns a todos os sujeitos e aos coletivos enquanto sujeitos; uma característica eles tem em comum, que é a forma multitudinária de mover-se e articular-se.

Nesse sentido, os coletivos tem como princípios basilares pelos quais se guiam e conformam um conjunto característico comum que os compõe, a horizontalidade, a não institucionalidade, a temporalidade e a auto-organização, o que demonstra uma atividade organizada e orientada de forma múltipla e plural que movimenta-se das mais variadas formas não institucionais de mobilização e participação democrática (PÉREZ; SILVA FILHO, 2017). Essa perspectiva é que coloca os coletivos no centro do surgimento de novos movimentos sociais não institucionalizados e não hierarquizados que demandam, para além de uma reordenação das instituições e esferas de participação democráticas tradicionais, a construção de uma nova democracia, ou de um novo projeto democrático. 
Ainda em comum, está a luta por direitos, que, em que pese, liguem-se às singularidades dos sujeitos que compõe as próprias lutas e os coletivos, são direitos comuns que perpassam as postulações identitárias, e com isso as formas institucionais de concretização e disputa política engendradas pelo Estado-nação, e tomadas de assalto pelo "Império". Porquanto, para que esses novos sujeitos multitudinários, os coletivos, coloquem-se efetivamente enquanto sujeitos políticos é necessária uma nova forma de pensar e fazer democráticos, ou seja, é necessário a constituição de um novo projeto democrático que abarque toda essa complexidade, e toda essa multiplicidade das singularidades em movimento. Para tanto, propõe-se a construção de uma “democracia-em-comum” radical e constituinte.

\section{A PROPOSTA DE UMA DEMOCRACIARADICAL E CONSTITUINTE COMO LUGAR DE FALA DOS COLETIVOS ENQUANTO SUJEITOS MULTITUDINÁRIOS}

Nesse caminho, os coletivos enquanto novos sujeitos políticos, e, ao mesmo tempo como uma nova forma de organização multitudinária das singularidades, podem e devem constituir-se de maneira efetiva propondo um novo projeto democrático, com novas instituições, e novas formas de participação política capazes de engendrar as lutas por direitos sem que as mesmas sejam capturadas pelas malhas do Estado e pelas estruturas de controle biopolítico do "Império".

Dessa forma, é necessário que se pense democracia a partir de um outro e novo prisma, que é o do poder constituinte propriamente dito, ou seja, não se pensa a partir de agora o poder constituinte inserido na tradição dos constitucionalismos liberais e da democracia representativa. O que se busca no presente trabalho como projeto democrático condizente com os sujeitos multitudinários tem a marca da potência plural das singularidades, potência essa que é destituinte, constituinte e antagônica ao mesmo tempo. O poder constituinte, assim, é central na construção de novos espaços de luta, e de novos espaços políticos para novos sujeitos políticos como os coletivos.

Desse modo, as lutas contemporâneas por direitos de maneira bastante clara dão-se, ou pelo menos devem se dar num ambiente democrático e, ganha rela e significativa importância abordar o papel da democracia na atualidade e, sobremodo, a necessidade de se pensar um projeto democrático radical, antagônico e revolucionário. Esse projeto, dar-se-á a partir da ótica do poder constituinte, como um poder ligado à potência da multitudo, ou seja, um poder constituinte que é imanente e jamais se coloca de forma encapsulada sob as amarras do estatalismo ou do "Império". De acordo com Negri (2015), o poder constituinte revela-se como um devir democrático que se perpetua a partir da imanência dos próprios sujeitos que dão forma à “multidão". Poder constituinte e democracia se ligam e se fazem um constructo absoluto, uma totalidade democrática em eterna contradição e, por isso, não totalitária ou estanque.

Nesse momento, é necessário deixar claro que a constituição de um novo sujeito que abarque toda essa complexidade se dá em meio a um e sob a forma de um poder constituinte, que se mostra 
aberto, mutável e eminentemente antagônico, construído em uma práxis multitudinária que agrega as singularidades e apresenta uma "forma comum". O sujeito que se afigura é o que aparece a partir e através de um poder que se constitui indelevelmente uma eterna práxis, e que é ele mesmo uma práxis da potência do ser - das singularidades, dos sujeitos. O sujeito que toma forma não se constrói a partir de fórmulas pré-estabelecidas identitárias que o colocam como uma possibilidade meramente institucional de luta e resistência, mas sim, assume a "forma disforme" da "multidão".

Como bem refere Guimaraens (2016), o projeto democrático constituinte negriniano encontra como obstáculo as amarras teóricas, práticas e institucionais colocadas pelo próprio Estado para conter o poder constituinte da multidão sempre que necessário seja (fosse). Desde essa perspectiva é vital questionar-se "como refutar a ontologia subjacente ao pensamento constitucional hegemônico e como denunciar e enfrentar os cerceamentos desse mesmo pensamento à democracia" (GUIMARAENS, 2016, p. 140).

O poder constituinte é a práxis multitudinária dos movimentos sociais, é o corpo social tomando forma e se articulando pluralmente sem perder suas singularidades, sem abrir mão de sua composição subjetiva, mas, dando contornos a um novo sujeito que é por excelência constituinte, constituinte de uma prática libertadora e democrática assentada na potência dos que a constituem. (NEGRI, 2015). Poder e potência travam a partir das linhas dadas pela batalha entre poder constituinte e constituído, a sua própria batalha, e a disputa entre uma perspectiva democrática prática ou institucionalizada. Os coletivos enquanto novos sujeitos políticos e enquanto uma nova forma de organização da "multidão" são a potência transformadora e não um poder assujeitador, não são concebidos como formas jurídico-sociais acabadas, e sim, como projetos antagonistas sempre abertos, de resistência e luta.

Negri (2015) nos diz a partir das ideias de Maquiavel, que sempre que o ideal se realiza, se torna real, se materializa na imanência do acontecimento cotidiano, mesmo nesses casos a síntese não se realiza, e nesse sentido, mesmo quando as condições para democracia são dadas confluídas do poder constituinte o projeto democrático não se realiza por completo. Nesse sentido, a síntese não é feita, e o poder constituinte ao se tornar constituído se esvazia e perde a sua força transformadora e a sua forma antagonista. "O político é efeito do processo constitutivo, do movimento de composição da potência multitudinária que exprime a medida do direito civil [...] (GUIMARAENS, 2016, p. 141).

Dessa maneira, a democracia radical que se propõe não se baseia na escolha e na delegação, ela não se esvazia na representatividade que aprisiona o poder constituinte da "multidão". A radicalização da democracia se dá a partir das singularidades que se unem na multitudo, mas não se unificam, nesse novo projeto democrático o plural (a "multidão") não se transforma no uno (o povo), ao contrário, o plural se manifesta nas singularidades que constituem a "multidão" sob a forma do “comum”, mas não da unidade (NEGRI, 2016). Há uma contraposição ao projeto de democracia estatal-moderno, como também uma ressignificação dos conceitos e conteúdos do que se entende por poder constituído e constituinte. De acordo com Matos (2016), o poder constituinte na experiência democrática liberal (e atual) se mantém apenas como retórica, pois qualquer concepção não aprisionada 
de poder constituinte é por demais perigosa ao sistema político instituído, seja no âmbito do Estado ou do "Império".

"Por ser uma expressão radical da vontade democrática, o poder constituinte se opõe à representação e ao sistema de check and balances, apontando para o futuro, nunca para o passado, diferentemente do que ocorre com o constitucionalismo liberal" (MATOS, 2016, p. 70), que, embora, ainda poderosos democracia e constitucionalismo tradicionais (liberais), se esvaziam cada vez mais em um choque cotidiano entre os movimentos da "multidão" e as constrições provocadas pelas instituições e estruturas estatais ("imperiais") de poder. Nesse sentido, não pode haver um projeto democrático único, a partir de uma unidade abstratamente criada (o povo), nem a partir de determinadas identidades estanques que se desvelam e se limitam em si mesmas. De acordo com Negri (2016), a experiência democrática que se possibilita a partir da multitudo é um constructo imanente com base nas singularidades que constituem uma eterna abertura do poder constituinte ao real, à prática social, à potência em estado bruto.

A democracia radical encenada a partir do poder constituinte em oposição ao poder constituído é possível pela ação de um sujeito radical que é a "multidão". Na radicalidade dos sujeitos e das instituições é que se coloca a luta por direitos. A luta por direitos sai das esferas pública e privada e ressurge através do "comum" e de uma práxis comum, em que o ambiente político-democrático é redesenhado, é rearticulado. É o ambiente criado pelo poder constituinte, inventivo e sempre aberto às possibilidades de construção de um novo cenário e de novas subjetividades (HOFFMAM, 2019). Porquanto, como refere Negri (2016), essa abertura que caracteriza o desenho democrático radical e constituinte não quer dizer inacabamento, pois, em verdade, há um processo acabado em sua abertura, em sua imanência, em seu devir democrático-constituinte, um devir que é o devir dos próprios sujeitos em sua precariedade.

Sem dúvida alguma para que o exercício dos poderes e instituições políticas se modifique é necessária uma nova fome de pensar e fazer a democracia que dê conta dos novos movimentos sociais. É necessário que se relacione o papel dos coletivos, suas formas, estruturas, e meios de lutar, com a necessidade de a "multidão" constituir novas institucionalidades e novas lideranças que se diferenciem das instituídas pelo Estado, e das construídas ou apoderadas pelo "Império" (HARDT; NEGRI, 2018). É preciso de pronto deixar bastante claro, no sentido de que não reste qualquer dúvida, que pensar novas instituições e novas lideranças não implica cria-las com o selo do estatalismo, dentro do bojo das instituições sociais e políticas clássicas como os sindicatos e os partidos políticos, nem mesmo orientando-se dentro dos movimentos sociais mais tradicionais, como Movimento dos Trabalhadores Sem Terra (MST), Via Campesina, Movimento dos Trabalhadores Sem Teto (MTST), entre outros.

Como salientam Hardt e Negri (2018), bem como Scherer-Warren (2014), esses movimentos e organizações políticas e sociais trazem consigo modelos de organização vertical e hierárquica, um perfil de liderança política central(izada), a busca por institucionalização e pelas vias tradicionais da 
política, e, a partir dessas características já elencadas, e permanência temporal, ou seja, são organização e movimentos que se prolongam no tempo, não se "esgotam" na luta. Hardt e Negri (2018), quando retomam exemplos já trabalhados pelos mesmos autores em (HARDT; NEGRI; 2014b), deixam claro que os movimentos da multidão tem como características centrais a horizontalidade, a falta de hierarquia, e a ausência de uma liderança central que concentre a tomada de decisões.

Nesse ponto, é importante recuperar que os coletivos notabilizam-se pela orientação com base na horizontalidade, não institucionalidade, temporalidade e auto-organização, o que demarca objeto, plano e meios de ação, como também demarca a sua constituição como novas formas de organização da subjetividade em torno de movimentos sociais (PEREZ; SILVA FILHO, 2017). Esses novos movimentos sociais são marcados por uma intensa capacidade produtiva que se dá por determinado tempo, eis a temporalidade; também, eles surgem muitas vezes de movimentos "espontâneos" dos próprios sujeitos que se organizam entorno ao coletivo o constituindo, ou seja, não há uma proposta central de criação do coletivo, bem como não há uma organização centralizada, mas múltipla e expansiva, e eis a auto-organização; os coletivos não tem estruturas, cargos, setores, ou algo semelhante que denote algum tipo de hierarquia dentro do mesmo, como também não tem uma liderança exponencial, e surge a horizontalidade; e os coletivos, embora busquem abalar as instituições democráticas tradicionais ligadas ao Estado, também não buscam institucionalizar-se; não é desejo dos coletivos tornarem-se uma instituição democrática, mas sim agir enquanto sujeito político provocando a democracia à rearticular-se - temos aí a não institucionalidade.

Nesse contexto, a ligação dos coletivos com o poder constituinte é uma ligação prática, cotidiana; os coletivos precisam do poder constituinte, e o poder constituinte precisa dos coletivos como uma forma de rearticulação e de manifestação do poder constituinte da “multidão”. Para Hardt e Negri (2018), esses novos movimentos sociais trazem a condição de biopoliticamente se rebelar às estruturas estatais e “imperiais” como limitadoras da ação dos sujeitos multitudinários, ou castradoras dessas subjetividades se utilizando dos aparatos "imperiais" de controle, que assujeitam a prática inventiva da multitudo.

A partir das ideias de Hardt e Negri é possível afirmar que os coletivos têm um papel importantíssimo na ligação dos planos social e político, gerando uma simbiose entre democracia e subjetividades que faz da política o lugar da vida, da vivência, e não o locus de disputas abstratas por poder. Nesse ponto, é importante afirmar os coletivos como agentes da mudança, como uma possibilidade de organizar novas formas e estruturas institucionais que tragam em si a marca da ação multitudinária, que se coloquem no campo democrático atual como instituições da "multidão". Com efeito:

Devemos ultrapassar de modo significativo quaisquer pressupostos relativos à soberania institucional. Como dissemos anteriormente, abandonarmos a soberania não significa abrirmos mão de autonomia ou autodeterminação. Significa deixarmos para trás, por um lado, a relação soberana entre poder e dominação e, por outro, o caráter mandatário da unidade. Durante essa transição, mais que nunca, a multidão necessita de instituições - não instituições que nos dominem, mas instituições que fomentem continuidade e organização, instituições que nos auxiliem na organização de nossas práticas, na gestão de nossas relações e em nossas tomadas conjuntas de decisão. (HARDT; NEGRI, 2018, p. 55). 
Nessa perspectiva, se não convém pensar, entender os coletivos como essas novas instituições que dão forma, estrutura, e meios de ação à "multidão", é possível e necessário perceber, compreender os coletivos como, no mínimo, um exemplo potencial de como devem se organizar e funcionar essas novas instituições, mesmo que com alguns ajustes, de modo a articular o político e o social - ou o político a partir do social. Pois como referem Hardt e Negri (2018, p. 95), "multidão compreendida como projeto político, é a articulação entre a ontologia social plural e a possibilidade de uma verdadeira democracia", e essa possibilidade se torna latente na articulação e movimentação dos coletivos, ao mesmo tempo como forma organizacional dos sujeitos e como eles mesmos sujeitos de uma nova democracia.

Os coletivos apontam para reais possibilidades de se conceber e articular instituições multitudinárias no plano da imanência, e não como instituições transcendentes que se colocam sobre os sujeitos. Hardt e Negri (2018) mostram necessidade aproveitando os movimentos que se constituem desde os zapatistas até a primavera árabe, os indignados na Espanha, o ocuppy wall street, os movimentos de junho de 2013 no Brasil, a luta campesina boliviana pela água e pelo gás, para a constituição de instituições multitudinárias duradouras no tempo, e não marcadas pelo signo da temporalidade e da desarticulação, da sonolência. Essa duração não é a construção de uma instituição à moda da modernidade, ou seja, institucionalizada espaço-temporalmente e marcada pela transcendência e imobilidade subjetiva, mas sim a necessidade que, mesmo ao fim dos ciclos de luta, há a necessidade de se produzir em comum, de desejar a reconstrução, e de se nutrir biopoliticamente pelo desejo da mudança.

Ao mesmo tempo, é imprescindível manter a forma horizontal de organização, ou seja, planejar instituições que sejam marcadas pela horizontalidade, mas que ao mesmo tempo, tenham uma liderança tática para os ciclos de luta. Essa liderança não é uma e central: ela é o espelho do desejo e da potência dos corpos, das singularidades que formam o "estar-em-comum", ela é a própria "multidão". O retorno às formas hierárquicas e centralizadas de organização e liderança é totalmente afastado, mas o enfrentamento antagônico da multitudo só se faz a partir de uma liderança que reflita taticamente os movimentos e desejos das singularidades e suas potências (HARDT; NEGRI, 2018). Aqui, ao mesmo tempo, a perspectiva auto-organizativa dos coletivos se mostra continuada, já que as novas instituições se articulam a partir dos movimentos da multitudo, porém, essas institucionalidades não se dão de forma espontânea, elas nascem de uma "fazer-ser-multidão" e de um "estar-em-comum" que é condição de possibilidade para a constituição de instituições multitudinárias.

A construção de instituições multitudinárias não implica oposição à não instituição dos coletivos, pois o que se propõe são novas instituições; é uma nova institucionalidade que seja marcada pelas características que conformam os coletivos, ou seja, são instituições não institucionais, pois não apreendidas pelas institucionalidades tradicionais. Há um projeto institucional e de reforma ao mesmo tempo, um projeto destituinte que descontrói as instituições na perspectiva da democracia tradicional liberal, e um projeto constituinte que constrói novas instituições que não tem a marca da unidade, da representatividade, e que não habitam a política tradicional, mas que ao contrário 
à abalam (HARDT; NEGRI, 2018). Há, nesse momento, um direito de "estar-em-comum" e de "ser-em-comum", um desejo de "estar-com-o-outro" e cooperar solidariamente que vai além e enfrenta as forças e estruturas estatais e "imperiais" e "impõe" a constituição de um novo espaço-tempo democrático.

Os coletivos são a materialização desse direito social à reunião de forma forte, pois, decorrente da potência dos corpos e do desejo de estar juntos, decorrente da força da produção social de direitos, desejos e capacidades, que colocam em cheque as instituições estatais democráticas tradicionais. Os coletivos são formas pelas quais os sujeitos multitudinários se organizam nas lutas por direitos a partir de suas singularidades e da pluralidade desses sujeitos e lutas. Não há uma limitação, ou uma identificação com a luta por determinados direitos, pois a luta que se faz no interior desses movimentos multitudinários é uma luta intransigente pelo "comum".

Os coletivos, então, não são essas novas instituições: eles são formas de organização dos sujeitos multitudinários, e, ao mesmo tempo, são sujeitos do processo de transformação proposto para a democracia. Esses novos sujeitos são o agente da radicalidade democrática proposta, eles são e tem o poder constituinte, ao mesmo tempo que são e fazem o movimento constitutivo desse novo arranjo democrático. Logo, os coletivos são compreendidos como sujeitos multitudinários que tem como lugar de fala um novo projeto democrático radical e constituinte que surge da luta, da resistência e do antagonismo da "multidão".

\section{CONSIDERAÇÕES FINAIS}

O que se evidencia com base no que foi construído durante o percurso teórico empreendido no presente trabalho, é que a "multidão" se coloca como um novo sujeito político e social que se movimenta desde dentro do Estado e do "Império", porém, de modo antagonista. Sob o signo da multitudo se originam novas formas associativas e cooperativas que engendram um projeto político-social assentado na preservação da pluralidade nas suas singularidades, sem apagar o singular e nem tornar uno o plural.

No contexto de constituição da "multidão", constrói-se novas formas de movimentos sociais que se originam das mais variadas maneiras e unindo as mais variadas características. Dentro desses novos movimentos sociais ganham destaque os coletivos, enquanto um novo sujeito político e social, e também como uma nova forma de organização das subjetividades. Os coletivos são evidenciados aqui como sujeitos que tem a marca do multitudinário, ou seja, como uma forma de "organização" da "multidão", e ao mesmo tempo como sujeitos multitudinários apresentando uma forma, estrutura e proposta (ação) diversas das instituições e sujeitos democráticos tradicionais.

Desse modo, conclui-se que a constituição dos coletivos como novos sujeitos políticos e sociais multitudinários contempla a possibilidade de instituição de uma nova forma de democracia 
radical e constituinte. Aqui, a proposta se dá em um duplo sentido compreendendo os coletivos como novos sujeitos político-sociais impulsionadores dessa nova democracia radical e constituinte e, ao mesmo tempo, como novas formas de "organização" das singularidades que servem de baliza para a constituição de uma nova institucionalidade democrática, ou seja, os coletivos apresentam o caminho para a constituição de uma nova liderança, de um novo princípio organizativo, de uma nova institucionalidade, que possibilitem a duração das lutas por direitos empreendidas por esses novos sujeitos.

\section{REFERÊNCIAS}

GONÇALVES, Fernando do Nascimento. Poéticas políticas, políticas poéticas: comunicação e sociabilidade nos coletivos artísticos brasileiros. Revista E-Compós, Brasília, V. 13, No 1, p. 1-14, jan-abr. 2010.

GUIMARAENS, Francisco de. O Poder Constituinte Segundo Antonio Negri: um conceito marxista e spinozista. Revista Direito e Práxis, Rio de Janeiro, V. 7, n. 4, p. 135-168, 2016.

HARDT, Michael; NEGRI, Antonio. Império. Tradução: Berilo Vargas. Rio de Janeiro: Record, 2002.

HARDT, Michael; NEGRI, Antonio. Bem Estar Comum. Tradução: Clóvis Marques.

Rio de Janeiro: Record, 2016.

HARDT, Michael; NEGRI, Antonio. Assembly: a organização multitudinária do comum. Tradução: Lucas Carpinelli; Jefferson Viel. São Paulo: Politeia, 2018.

HOFFMAM, Fernando. Do Cosmopolitismo ao "Comumpolitismo" Enquanto Um Novo Ambiente Para os Direitos Humanos na Era do Império. Rio de Janeiro: Lumen Juris, 2019.

MAGAlHÃES DE LIMA, Carlos Henrique. A Cidade em Movimento: práticas insurgentes no ambiente urbano. Revista Oculum Ensaios, Campinas, V. 12, № 1, p. 39-48, 2015.

MAIA, Gretha Leite. A Juventude e os Coletivos: como se articulam novas formas de expressão política. Revista Eletrônica do Curso de Direito UFSM, Santa Maria, V. 8, № 1, p. 58-73, 2013.

MATOS, Andityas Soares de Moura Costa. Filosofia Radical e Utopia: inapropriabilidade, an-arquia, a-nomia. Rio de Janeiro: Via Verita, 2014. 
MATOS, Andityas Soares de Moura Costa. Estado de Exceção, Desobediência Civil e Desinstituição: por uma leitura democrático-radical do poder constituinte, Revista Direito e Práxis, Rio de Janeiro, V. 7, n. 4, p. 43-95, 2016.

MAZIVIERO, Maria Carolina; ALMEIDA, Eneida de. Urbanismo Insurgente: ações recentes de coletivos urbanos ressignificando o espaço público na cidade de São Paulo. Anais do XVII ENANPUR, São Paulo, V. 17, No 1, p. 1-18, 2017.

NEGRI, Antonio. 5 Lições Sobre o Império. Tradução: Alba Olmi. Rio de Janeiro: DP\&A, 2003.

NEGRI, Antonio. Espinosa Subersivo e Outros Escritos.Tradução: Herivelto Pereira de Souza. Belo Horizonte: Autêntica, 2016.

PEREIRA, Simone Luci; GHEIRART, Oziel. Coletivos de música eletrônica em São Paulo: usos da cidade, culturas juvenis e sentidos políticos. Revista E-Compós, Brasília, v. 21, n. 3, p. 1-17, set-dez. 2018.

PEREZ, Olívia Cristina; SILVA FILHO, Alberto Luís Araújo. Coletivos: um balanço da literatura sobre as novas formas de mobilização da sociedade civil. Revista Latitude, Maceió, v. 11, n. 1, p. 255-294, 2017.

SCHERER-WARREN, Ilse. Dos Movimentos Sociais Às Manifestações de Rua: o ativismo brasileiro no século XXI. Revista Política e Sociedade, Florianópolis, v. 13, n. 28, p.13-34, set-dez. 2014. 
